\title{
ACOUSTICAL REFLECTION AND SCATTERING FROM THE UNDERSIDE OF LABORATORY-GROWN SEA ICE: MEASUREMENTS AND PREDICTIONS
}

\author{
(Abstract) \\ by \\ K.C. Jezek \\ (Dartmouth College, Hanover, NH 03755, and NASA, Washington, DC 20546, U.S.A.) \\ with
}

T.K. Stanton

(University of Wisconsin, Madison, WI 53706, U.S.A.)

and

A.J. Gow

(U.S. Army Cold Regions Research and Engineering Laboratory, Hanover, NH 03755, U.S.A.)

\begin{abstract}
We have studied acoustical reflection and scattering properties of the underside of laboratory-grown sea ice. Our purpose was to determine the morphologic characteristics of undeformed sea ice that control acoustic scattering and reflection. So our experiments included both detailed studies of the structure of the ice as well as the application of a variety of acoustic methods.

Ice sheets were grown in an outdoor pond (about $6 \mathrm{~m}$ by $13 \mathrm{~m}$ by $1.5 \mathrm{~m}$ ) and exhibited features characteristic of undeformed, cold sea ice: an upper granular zone; a columnar zone of crystals with cross-sectional areas of about $1 \mathrm{~cm}^{2}$; vertical sheets of brine pockets; a bulk salinity of $9.1 \%$ distributed over $9 \mathrm{~cm}$ of ice; a dendritic interface at the ice/water boundary with dendrites about $0.5 \mathrm{~mm}$ across at the time of our measurements. Echo-amplitude fluctuations of normal-incidence sonar pings $(100 \mathrm{kHz}$ to $800 \mathrm{kHz}$ ) were measured as the sonars moved horizontally under the ice and accumulated into echo-amplitude histograms. (Data from a deteriorating ice sheet as well as
\end{abstract}

data on lake ice were also collected.) We fitted the Rice probability density function (PDF) to the data and combined the resultant statistical parameter with Eckart acoustic scattering theory. The reflection coefficients calculated using this method ranged from 0.06 to 0.12 , depending on environmental conditions. RMS roughness calculated using data from new sea ice was estimated to be about $0.3 \mathrm{~mm}$. Because our ice thin sections show the ice to be porous and permeable at the interface with dendrites $0.5 \mathrm{~mm}$ thick, we suspect that the dendrites control the scattering as described by the echo-amplitude histograms. Further, we attribute the low reflection coefficients to the dendritic structure which may act as an impedance-matching zone into the columnar section of the sea ice.

Transmission measurements were performed by positioning a transducer located at the ice/air interface directly over the transducer located in the water. The total attenuation through $18 \mathrm{~cm}$ of ice ranged from $12 \mathrm{~dB}$ at $50 \mathrm{kHz}$ to $70 \mathrm{~dB}$ at $420 \mathrm{kHz}$ (signal levels were measured relative to the same path in water).

\section{A BACK-PORTABLE MICROPROCESSOR-BASED IMPULSE RADAR SYSTEM}

\author{
(Abstract) \\ by \\ F.H.M. Jones, B.B. Narod and G.K.C. Clarke \\ (Department of Geophysics and Astronomy, University of British Columbia, Vancouver, British \\ Columbia V6T 1 W5, Canada)
}

\begin{abstract}
We have developed and tested a portable impulse radar for ground-based sounding of glaciers. Noteworthy characteristics of the instrument are its portability, low power consumption, digital data storage, and the ability to be operated either manually or automatically under program control. Current system specifications include a band width of $46 \mathrm{MHz}$; a sampling interval of $10.76 \mathrm{~ns}$; depth precision of $0.9 \mathrm{~m} ; 1024$ samples per record; amplitude resolution of 8 bits; minimum recordable signal at the receive antenna equal to $0.26 \mathrm{mV}$; an operating center frequency of 8.5 $\mathrm{MHz}$ and an antenna-damping coefficient of $300 \mathrm{ohms}$.

The transmitter uses paired SCRs and a $12 \mathrm{~V}$ to $800 \mathrm{~V}$ converter to impress a $1200 \mathrm{~V}$ step on to a resistively damped dipole antenna. This pulse is triggered from the receiving system via a fibre optics cable so that each record can include the complete surface-path wavelet. The receiver
\end{abstract}

unit combines a wide-band amplifier (with variable front-end attenuation) with a microprocessor-controlled data-acquisition system of our own design. The result of each sounding can be replayed as an "A-scope" display on a small, low-cost oscilloscope and stored on or retrieved from digital cassettes. In the unattended mode, records are collected at programmable intervals. The system weighs about $7.5 \mathrm{~kg}$ and uses dry cells or rechargeable batteries for power.

Examples were presented in a poster session of sounding profiles taken in July 1986 on Trapridge Glacier, Yukon Territory in Canada, along lines coinciding with an extensive drilling program. Although not yet fully analysed, we feel that some of the results may represent the effects of crevasses, internal features such as morainal material, varying bed features, and changes in subglacial and englacial hydrology. 